\title{
Distributed coordinated active and reactive power control of wind farms based on
} model predictive control

Guo, Yifei; Gao, Houlei; Wu, Qiuwei; Østergaard, Jacob; Yu, Dachuan; Shahidehpour, Mohammad

Published in:

International Journal of Electrical Power and Energy Systems

Link to article, DOI:

10.1016/j.ijepes.2018.06.043

Publication date:

2018

Document Version

Peer reviewed version

Link back to DTU Orbit

Citation (APA):

Guo, Y., Gao, H., Wu, Q., Østergaard, J., Yu, D., \& Shahidehpour, M. (2018). Distributed coordinated active and reactive power control of wind farms based on model predictive control. International Journal of Electrical Power and Energy Systems, 104, 78-88. https://doi.org/10.1016/j.ijepes.2018.06.043

\section{General rights}

Copyright and moral rights for the publications made accessible in the public portal are retained by the authors and/or other copyright owners and it is a condition of accessing publications that users recognise and abide by the legal requirements associated with these rights.

- Users may download and print one copy of any publication from the public portal for the purpose of private study or research.

- You may not further distribute the material or use it for any profit-making activity or commercial gain

- You may freely distribute the URL identifying the publication in the public portal 


\title{
Distributed Coordinated Active and Reactive Power Control of Wind Farms Based on Model Predictive Control
}

\author{
Yifei $\mathrm{Guo}^{\mathrm{a}, \mathrm{b}}$, Houlei Gao ${ }^{\mathrm{a}, *}$, Qiuwei $\mathrm{Wu}^{\mathrm{b}}$, Jacob Østergaard ${ }^{\mathrm{b}}$, Dachuan $\mathrm{Yu}^{\mathrm{a}}$, Mohammad Shahidehpour ${ }^{\mathrm{c}}$ \\ ${ }^{a}$ Key Laboratory of Power System Intelligent Dispatch and Control of Ministry of Education, Shandong University, China \\ ${ }^{b}$ Center for Electric and Energy, Department of Electrical Engineering, Technical University of Denmark(DTU), Denmark \\ ${ }^{c}$ Department of Electrical and Computer Engineering, Illinois Institute of Technology(IIT), USA
}

\begin{abstract}
This paper proposes a distributed coordinated active and reactive power control scheme for wind farms based on the model predictive control (MPC) along with the consensus-based distributed information synchronization and estimation, which can optimally dispatch the active power of wind turbines (WTs) and regulate the voltages within the wind farm. For the active power control, the pitch angle and generator torque of WTs are optimally controlled to alleviate fatigue loads of WTs while tracking the power reference of the wind farm required by system operators. For the reactive power/voltage control, the reactive power outputs of WTs are controlled to mitigate the voltage deviations and simultaneously optimize reactive power sharing. Considering the high $R / X$ ratio of the wind farm collector systems, the impact of active power variations on voltages is taken into account to improve the voltage regulation. The proposed scheme is center-free and only requires sparse communication network. Each WT only exchanges information with its immediate neighbors and the local optimal control problems are solved in parallel, implying good scalability and flexibility for large-scale wind farms. The predictive model of a WT is derived and then the MPC problem is formulated. A wind farm with ten WTs was used to verify the proposed control scheme.
\end{abstract}

Keywords: active power control, consensus protocol, distributed control, model predictive control, reactive power control, voltage control, wind farm.

\begin{tabular}{|c|c|c|c|}
\hline \multicolumn{4}{|c|}{ Nomenclature } \\
\hline$(*)_{0}$ & measurement at operating point & $\lambda$ & tip speed ratio \\
\hline$\Delta(*)$ & incremental value of variable & $\beta$ & auxiliary variable in pitch control \\
\hline$(\hat{*})^{(i)}$ & variables estimated by WT- $i$ & $Q_{\mathrm{W}}$ & reactive power otuput of WT \\
\hline$P_{\text {ref }}^{\mathrm{WT}}$ & active power reference of $\mathrm{WT}$ & $Q_{\mathrm{ref}}^{\mathrm{WT}}$ & reactive power reference of $\mathrm{WT}$ \\
\hline$P_{\mathrm{g}}$ & active power output of WT & $Q_{\text {meas }}^{\mathrm{WT}}$ & measured reactive power \\
\hline$\omega_{\mathrm{r}}$ & rotor speed & $Q_{\mathrm{int}}^{\mathrm{WT}}$ & auxiliary variable in reactive power control \\
\hline$\omega_{\mathrm{g}}, \omega_{\mathrm{f}}$ & generator and filtered speed & $V_{S}$ & terminal voltage of the grid side converter \\
\hline$\theta, \theta_{\text {ref }}$ & pitch angle and its reference & $i_{q}, i_{\mathrm{qref}}$ & q-axis current and its reference \\
\hline$T_{\mathrm{r}}$ & aerodynamics torque & $P_{\mathrm{ref}}^{\mathrm{WF}}$ & wind farm power reference \\
\hline$F_{\mathrm{t}}$ & thrust force & $P_{\mathrm{avi}}^{\mathrm{WF}}$ & available power of wind farm \\
\hline$T_{\mathrm{g}}, T_{\text {gref }}$ & generator torque and its reference & $\bar{P}_{\mathrm{avi}}^{\mathrm{WT}}$ & average available power of WTs \\
\hline$T_{\mathrm{s}}$ & shaft torque & $V_{\text {ref }}$ & voltage reference \\
\hline$v_{\mathrm{W}}$ & effective wind speed & $V_{\mathrm{POC}}$ & voltage at the $\mathrm{POC}$ \\
\hline$C_{\mathrm{p}}$ & power efficient & $V_{\mathrm{W}}$ & voltage at WT bus \\
\hline$C_{\mathrm{t}}$ & thrust efficient & $N$ & number of WTs \\
\hline$H_{p}$ & prediction horizon & $H_{c}$ & control horizon \\
\hline$N_{p}$ & prediction step & $N_{c}$ & control step \\
\hline$T_{c}$ & control period & $\bar{Q}_{W}, Q_{W}$ & reactive power limits of $\mathrm{WT}$ \\
\hline
\end{tabular}

* Corresponding author

Email address: houleig@sdu.edu.cn (Houlei Gao) 


\section{Introduction}

Wind energy has been developing rapidly due to the growing concerns over environmental issues around the world. As the wind power penetration level increases, its variability and uncertainty have brought a number of technical and economic challenges for power system operation [1]. Wind farms are required to meet the technical requirements specified in grid codes issued by system operators. With the fast development of modern wind turbine (WT) technologies, the controllability and fast-response capability of wind power are significantly improved. Modern wind farms are able to provide multiple ancillary services such as grid frequency and voltage support [2], 3].

Generally, wind farm control applications may consist of several control objectives including active power dispatch and reactive power/voltage control [4. Due to the decoupled control loops of active and reactive power of modern WTs, they are often separately designed.

For active power control, several control strategies such as proportional distribution [5]-[6] and proportional-integral (PI) control [7] are easy to be implemented. However, these dispatch methods mainly focus on power reference tracking of the wind farm without considering fatigue loads experienced by the WTs, which have significant impacts on the lifetime of WTs. In recent years, the optimization-based control strategies have been widely studied [8]-10]. The optimal control problems are formulated as multi-objective optimization problems which can achieve power tracking as well as reduce the fatigue loads of WTs.

For reactive power control of wind farms, the main aim is to maintain the voltage at the point of connection (POC) within the feasible range, which is specified in many grid codes. Several reactive power dispatch strategies based on the proportional distribution and PI controller have been proposed in [4, [10]-[11, which depend on the voltage at the POC and available reactive power capability of WTs while the terminal voltages of WTs are not considered. The optimizationbased reactive power/voltage control strategies have also been proposed [12]-[14]. In [12, a hierarchical automatic voltage controller based on the sensitivity method was designed and implemented in a wind power base of northern China. In [13- 14], the optimal power flow-based control strategies for high-voltage-direct-current (HVDC) connected offshore wind farms were proposed, in which the objectives are to minimize the active power losses of the offshore system.

As a special optimization-based method, model predictive control (MPC) has been widely used in wind power systems both in WT level [15]-[16] and wind farm level [17]-[22]. In [17, a MPC scheme was proposed to balance the wind farm power reference tracking as well as fatigue loads reduction. In [18]-20, the distributed MPC (D-MPC) shemes were proposed for optimal active power dispatch for wind farms, in which the optimal control problems are solved by the distributed optimization algorithms, hoewever, in which a central unit is also required for WT coordination to track the power reference required by system operators. In [21]-222, the centralized MPC-based coordinated wind farm voltage control schemes were designed. In [21], the reactive power sources inside a wind farm including WTs, static Var compensators and on-load tap changing transformer are optimally coordinated. In 22, WTs and wind farm side HVDC converter are optimally coordinated.

In the centralized optimization-based voltage control schemes [12]-[14, [17]-[22, the wind farm is modeled as a constrained multiple input and multiple output system whose order drastically grows as the number of WTs increases. As the number of WTs increases, the computation burden of the central controller will be heavy. Moreover, the cost of the communication infrastructures may be quite high for large-scale wind farms. Distributed control is appealing for the wind farm control since a wind farm consists of a number of WTs, which has a high degree autonomy. Besides, the typical $R / X$ ratio of the wind farm collector system is high and consequently voltages are sensitive to variations in active power injections. The conventional active and reactive power control schemes of wind farms were designed in a separated manner, which neglects the impact of active power variations of WTs on system voltages and consequently voltage control performance might not be optimal.

In this context, the main contribution of this paper is a distributed coordinated active and reactive power control design which aims to optimally regulate active and reactive power outputs of WTs in a wind farm. For the active power control, the controllers reduce the fatigue loads of WTs while tracking the wind farm power reference. For the reactive power control, the voltages are regulated and reactive power sharing is optimized. The impact of active power variations on voltages is taken into account to improve the voltage control. The global reference information including the power reference of the wind farm and voltage at the POC is synchronized by a distributed finite-time observer. The total available active power of the wind farm is estimated using a distributed estimator based on the average-consensus protocol. 


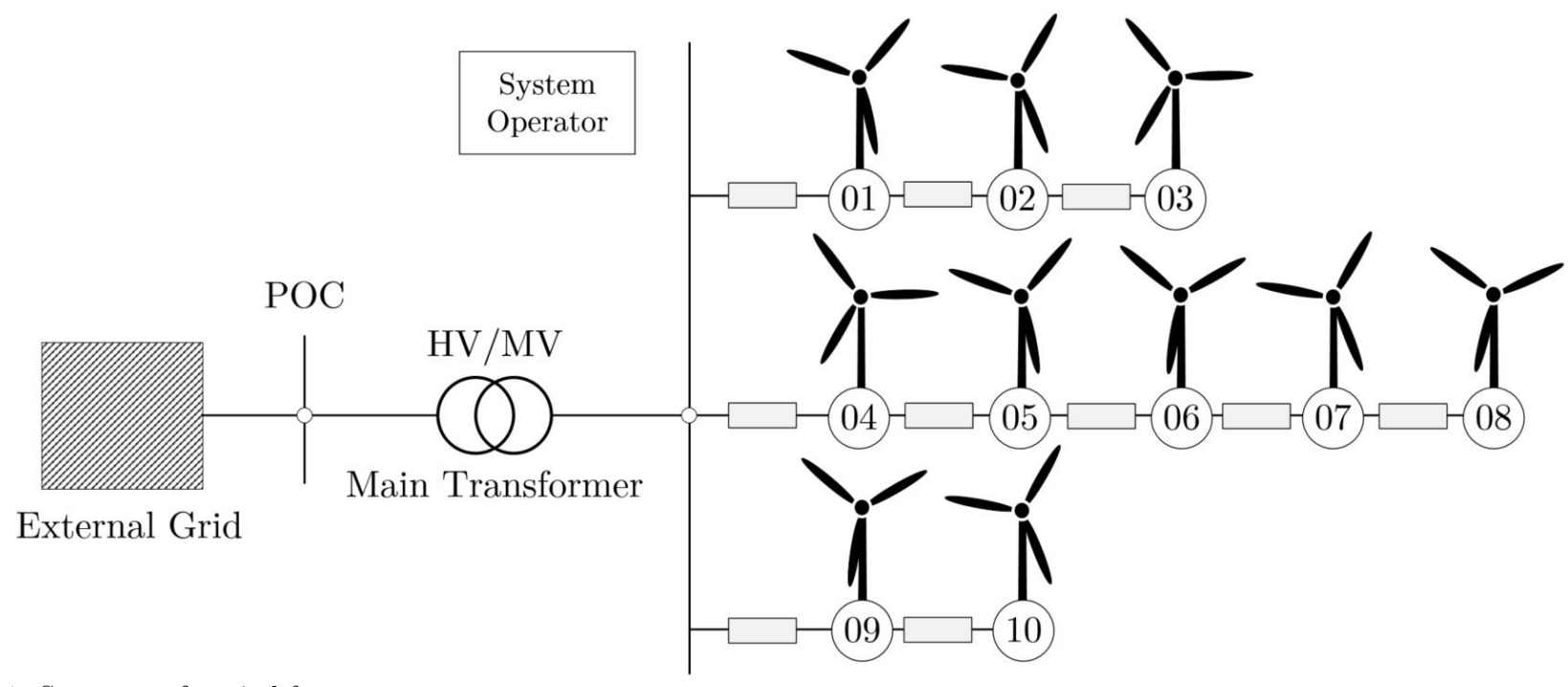

Figure 1: Structure of a wind farm.

Compared with the traditional centralized control, the proposed distributed control scheme has several advantages as follows: 1) Eliminate the requirement of a central controller; 2) Reduce the cost of communication infrastructures (All WTs only exchange information with their immediate neighbors, and when the wind farm is expanded, the newly connected WTs are only required to build the communication link with the neighboring WTs instead of the far central controller); 3) Reduce the computation burden. (the computation in each WT controller is in parallel and the computation burden is less dependent on the number of WTs); 4) Improve the scalability of the wind farm controller.

The rest of this paper is organized as follows. Section 2 presents an overview of the proposed control scheme. In Section 3, the predictive models of WTs regarding active and reactive power control loops are described. In Section 4, the formulation of the distributed optimal control problem is presented. Simulation results are presented and discussed in Section 5 followed by conclusions.

\section{Distributed MPC Based Power Control Scheme Design for Wind Farms}

The typical structure of a wind farm is shown in Fig. 1. Each WT is equipped with a distributed WT controller and a sparse, connected communication network is designed for the distributed power control scheme.

The configuration of the proposed distributed coordinated power controller (DCPC) is illustrated in Fig. 22, The exchanged information between the system operator (or wind farm operator) and the leader WT is the wind farm power reference. The information between two neighboring WTs includes the estimated available power of the wind farm, the estimated power reference of wind farm, the estimated voltage at the POC and the predicted active/reactive power outputs. At each control point, each DCPC sends the required information to its immediate neighbors and receives the corresponding information from its neighbors.

The total available power of the wind farm is estimated by the distributed estimator which is executed every few seconds. The global reference information including the wind farm power reference and voltage at the POC are synchronized by the distributed finite-time observer. The sensitivity coefficients of bus voltage with respect to power injections are given to each DCPC. For the sensitivity calculation, one option is to use offline power flow analysis and keep constant, which may lead to significant errors. Another option is updating the sensitivity in every control period, whereas it might lead to heavy computation and communication burden. Thus, considering the operation states cannot dramatically change in a short term, the sensitivity coefficients are updated with low frequency in this study. An analytical sensitivity calculation method first developed for radial distribution networks is adopted in this paper [23. It is expected that the closed-loop nature of MPC will compensate infrequently updated sensitivity coefficients.

The objective of the D-MPC for wind farms includes two parts: 1) active power dispatch; and 2) reactive power/voltage control. For the active power control, the controller minimizes the fatigue loads of WTs while tracking the power reference of the wind farm required by system operators, which is considered as a soft constraint and explicitly expressed in the 


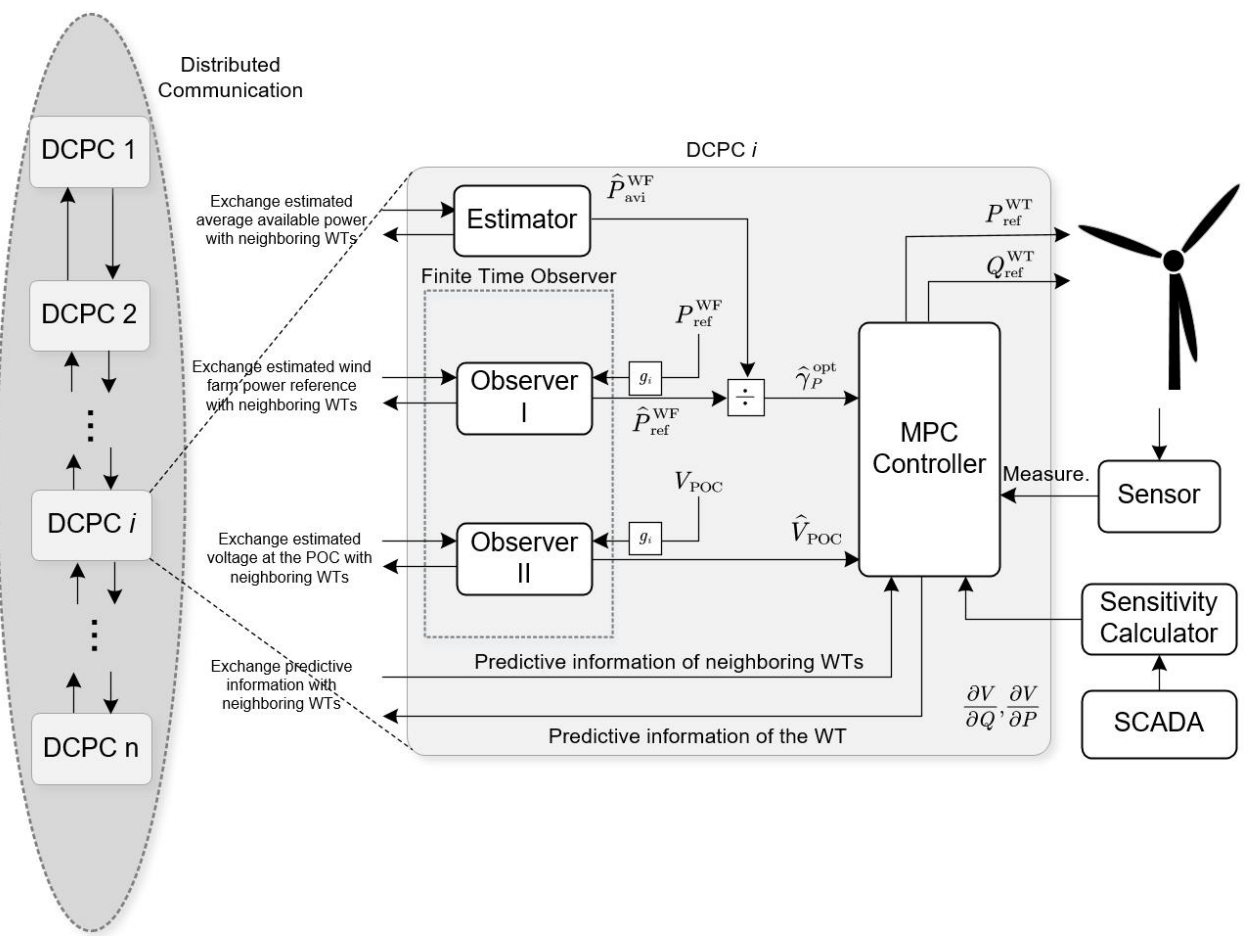

Figure 2: Distributed coordinated active and reactive power control scheme.

objective function. For the reactive power control, the voltages at the POC and WT buses are all taken into consideration. In addition, the fair reactive power sharing is also addressed. To better regulate the voltages, the impact of active power variations on voltages is considered.

\section{Predictive Model of a WT}

In this section, the incremental state-space models of the WT including active and reactive power control loops are obtained by linearizing the nonlinear WT model at the operating point.

\subsection{Active Power Control Loop}

Modern WTs can be controlled to operate in the maximum power point tracking (MPPT) mode or a derated mode to track the power reference sent from the DCPC. The power-controlled WT model developed by the National Renewable Energy Laboratory (NREL) is used to represent a variable speed WT for modeling of the active power control loop. The configuration of a power-controlled WT model is illustrated in Fig. 3 [24.

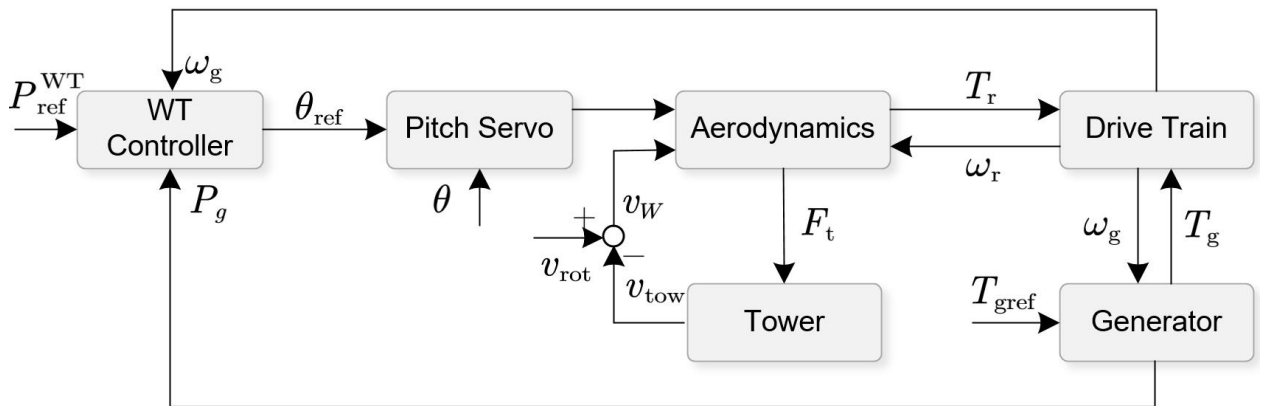

Figure 3: Structure of a power-controlled WT [24]. 


\subsubsection{Modeling}

According to Fig. 3, a pitch-controlled WT can be approximately modeled by [8], 24,

$$
\left\{\begin{aligned}
T_{\mathrm{r}} & =\frac{0.5 \pi \rho R^{2} v_{\mathrm{W}}^{3} C_{\mathrm{p}}(\lambda, \theta)}{\omega_{\mathrm{r}}} \\
F_{\mathrm{t}} & =0.5 \pi \rho R^{2} v_{\mathrm{W}}^{2} C_{\mathrm{t}}(\lambda, \theta) \\
\dot{\omega}_{\mathrm{r}} & =\frac{1}{J_{\mathrm{t}}}\left(T_{\mathrm{r}}-\eta T_{\mathrm{g}}\right) \\
\omega_{\mathrm{g}} & =\eta \omega_{\mathrm{r}} \\
J_{\mathrm{t}} & =J_{\mathrm{r}}+\eta^{2} J_{\mathrm{g}} \\
T_{\mathrm{s}} & =\frac{\eta^{2} J_{\mathrm{g}}}{J_{\mathrm{t}}} T_{\mathrm{r}}+\frac{\eta J_{\mathrm{r}}}{J_{\mathrm{t}}} T_{\mathrm{g}} \\
T_{\mathrm{g}} & \approx T_{\mathrm{g}}^{\text {ref }}
\end{aligned}\right.
$$

The generator torque and pitch controller can be modeled by [8], 24,

$$
\left\{\begin{aligned}
T_{\mathrm{g}}^{\text {ref }} & =\frac{P_{\text {ref }}^{\mathrm{WT}}}{\mu \omega_{\mathrm{f}}} \\
\dot{\omega}_{\mathrm{f}} & =-\frac{1}{\tau_{\mathrm{f}}} \omega_{\mathrm{f}}+\frac{1}{\tau_{\mathrm{f}}} \omega_{\mathrm{g}} \\
\theta_{\text {ref }} & =\frac{K_{\mathrm{p}}^{\theta}}{K_{0}+K_{1} \theta_{\text {ref }}}\left(\omega_{\mathrm{f}}-\omega_{\mathrm{g}}^{\text {rated }}\right)+\frac{K_{\mathrm{i}}^{\theta}}{K_{0}+K_{1} \theta_{\text {ref }}} \frac{\left(\omega_{\mathrm{f}}-\omega_{\mathrm{g}}^{\text {rated }}\right)}{s} \\
\beta & =\left(K_{0}+K_{1} \theta\right) \theta
\end{aligned}\right.
$$

More details about the pitch-controlled WT can be referred to [8]. The definations of these variables are presented in the Appendix.

\subsubsection{Incremental State-Space Model}

The modeling of physical and control systems has been presented above. Based on the linearization of the simplified nonlinear WT model at the operating point, the incremental state-space model can be obtained. Define $\Delta x_{p}:=$ $\left[\Delta \omega_{\mathrm{g}}, \Delta \omega_{\mathrm{f}}, \Delta \beta\right]^{\mathrm{T}}$ is the state variable vector, $\Delta y_{p}:=\left[\Delta T_{\mathrm{s}}, \Delta F_{\mathrm{t}}\right]^{\mathrm{T}}$ is the output variable vector, and $\Delta u_{p}:=\left[\Delta P_{\mathrm{ref}}^{\mathrm{WT}}\right]^{\mathrm{T}}$ is the control input. Based on (1) and (2), the linearized incremental state-space model of the active power control loop can be represented as,

$$
\begin{aligned}
\Delta \dot{x}_{p} & =\boldsymbol{A}_{p} \Delta x_{p}+\boldsymbol{B}_{p} \Delta u_{p}+\boldsymbol{E}_{p} \\
\Delta y_{p} & =\boldsymbol{C}_{p} \Delta x_{p}+\boldsymbol{D}_{p} \Delta u_{p}
\end{aligned}
$$

with

$$
\begin{gathered}
\boldsymbol{A}_{p}=\left[\begin{array}{ccc}
\frac{\eta}{J_{\mathrm{t}}} \frac{\partial T_{\mathrm{r}}}{\partial \omega_{\mathrm{g}}} & \frac{\eta^{2} P_{\mathrm{g} 0}}{J_{\mathrm{t}} \omega_{\mathrm{f} 0}^{2}} & \frac{\eta}{J_{\mathrm{t}}} \frac{\partial T_{\mathrm{r}}}{\partial \beta} \\
\frac{1}{\tau_{\mathrm{f}}} & -\frac{1}{\tau_{\mathrm{f}}} & 0 \\
\frac{K_{\mathrm{p}}^{\theta}}{\tau_{r m f}} & -\frac{K_{\mathrm{p}}^{\theta}}{\tau_{\mathrm{f}}}+K_{\mathrm{i}}^{\theta} & 0
\end{array}\right], \boldsymbol{B}_{p}=\left[\begin{array}{c}
\frac{\eta^{2} P_{\mathrm{g} 0}}{J_{\mathrm{t}} \omega_{\mathrm{f} 0}^{2}} \\
0 \\
0
\end{array}\right], \boldsymbol{C}_{p}=\left[\begin{array}{ccc}
\frac{\eta^{2} J_{\mathrm{g}}}{J_{\mathrm{t}}} \frac{\partial T_{\mathrm{r}}}{\partial \omega_{\mathrm{g}}} & \frac{\eta J_{\mathrm{r}} P_{\mathrm{g} 0}}{\mu J_{\mathrm{t}} \omega_{\mathrm{f} 0}^{2}} & \frac{\eta^{2} J_{\mathrm{g}}}{J_{\mathrm{t}}} \frac{\partial T_{\mathrm{r}}}{\partial \beta} \\
\frac{\partial F_{\mathrm{t}}}{\partial \omega_{\mathrm{g}}} & 0 & \frac{\partial F_{\mathrm{t}}}{\partial \beta}
\end{array}\right], \\
\boldsymbol{D}_{p}=\left[\begin{array}{c}
\frac{\eta J_{\mathrm{r}}}{\mu J_{\mathrm{t}} \omega_{\mathrm{f} 0}} \\
0
\end{array}\right], \boldsymbol{E}_{p}=\left[\begin{array}{c}
\frac{\eta}{J_{\mathrm{t}}}\left(T_{\mathrm{r} 0}-\eta T_{\mathrm{g} 0}\right) \\
0 \\
K_{\mathrm{i}}\left(\omega_{\mathrm{f} 0}-\omega_{\mathrm{g}}^{\mathrm{rated}}\right)
\end{array}\right]
\end{gathered}
$$

where the coefficients $\frac{\partial T_{\mathrm{r}}}{\partial \omega_{\mathrm{g}}}, \frac{\partial T_{\mathrm{r}}}{\partial \beta}, \frac{\partial F_{\mathrm{t}}}{\partial \omega_{\mathrm{g}}}$ and $\frac{\partial F_{\mathrm{t}}}{\partial \beta}$ are derived from the Taylor approximation of $T_{\mathrm{r}}$ and $F_{\mathrm{t}}$ at the operating point. The discrete model can be obtained by discretizing the continuous state-space model (3) with the sampling time $\Delta \tau_{s}$

$$
\begin{aligned}
\Delta x_{p}(k+1) & =\boldsymbol{A}_{p}^{\mathrm{d}} \Delta x_{p}(k)+\boldsymbol{B}_{p}^{\mathrm{d}} \Delta u_{p}(k)+\boldsymbol{E}_{p}^{\mathrm{d}} \\
\Delta y_{p}(k) & =\boldsymbol{C}_{p}^{\mathrm{d}} \Delta x_{p}(k)+\boldsymbol{D}_{p}^{\mathrm{d}} \Delta u_{p}(k)
\end{aligned}
$$

where $\boldsymbol{A}_{p}^{\mathrm{d}}=e^{\boldsymbol{A}_{p} \Delta \tau_{\mathrm{s}}}, \boldsymbol{B}_{p}^{\mathrm{d}}=\int_{0}^{\Delta \tau_{\mathrm{s}}} e^{\boldsymbol{A}_{p} \tau} \boldsymbol{B}_{p} d \tau, \boldsymbol{E}_{p}^{\mathrm{d}}=\int_{0}^{\Delta \tau_{\mathrm{s}}} e^{\boldsymbol{A}_{p} \tau} \boldsymbol{E}_{p} d \tau, \boldsymbol{C}_{p}^{\mathrm{d}}=\boldsymbol{C}_{p}, \boldsymbol{D}_{p}^{\mathrm{d}}=\boldsymbol{D}_{p}$. 


\subsection{Reactive Power Control Loop}

\subsubsection{Modeling}

For full-scale converter WTs, the grid side converter can be controlled to provide reactive power support for the grid. A standard control scheme for voltage source converter, consisting of the cascaded control structure (inner loop and outer loop), is implemented in this study. For the active power loop, the dc voltage is controlled at the nominal value. For the q-axis control loop, the reactive power control mode is adopted as illustrated in Fig. 4.

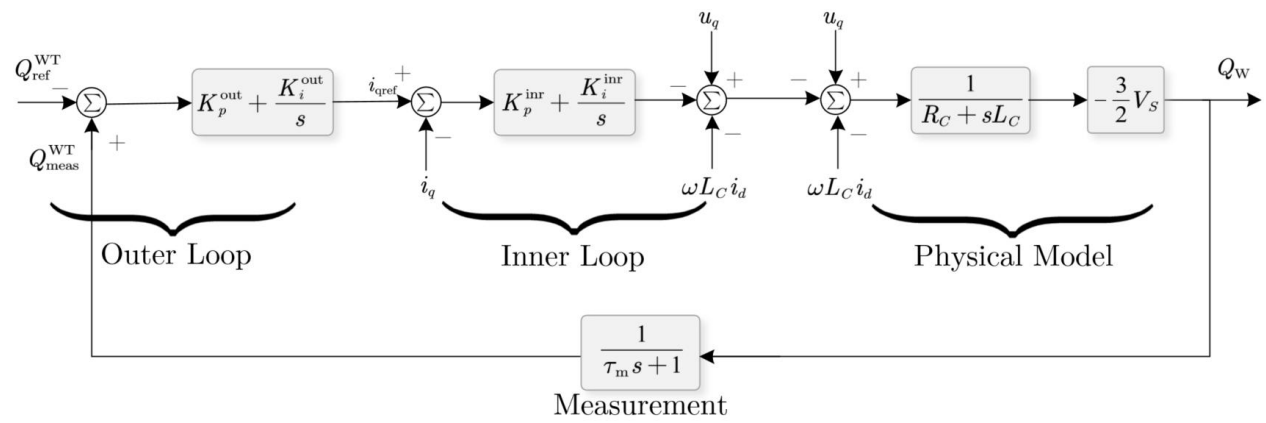

Figure 4: Structure of the reactive power control loop.

By introducing the feedforward terms $\omega L_{C} i_{d}$ and $\omega L_{C} i_{q}$, the $P$-control loop and $Q$-control loop are decoupled. And by selecting,

$$
K_{\mathrm{P}}^{\mathrm{inr}}=\frac{L_{C}}{\tau_{\mathrm{inr}}}, K_{\mathrm{I}}^{\mathrm{inr}}=\frac{R_{C}}{\tau_{\mathrm{inr}}}
$$

the whole system can be simplified as Fig. 5.

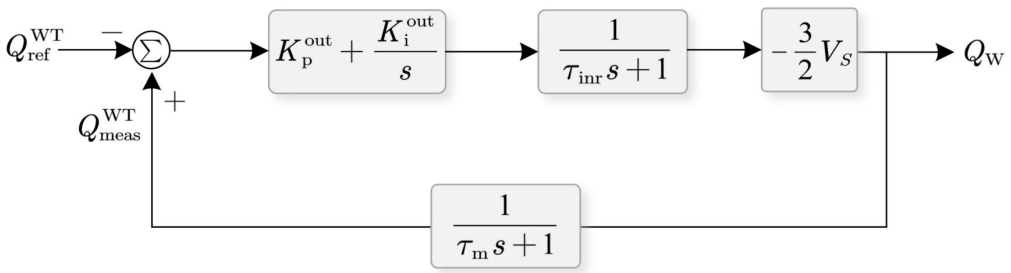

Figure 5: Simplified equivalent control loop.

Accordingly, the basic formulation of the reactive power control can be expressed as,

$$
\begin{cases}i_{q}^{*}= & K_{\mathrm{p}}^{\mathrm{out}}\left(Q_{\mathrm{meas}}^{\mathrm{WT}}-Q_{\mathrm{ref}}^{\mathrm{WT}}\right)+K_{\mathrm{i}}^{\mathrm{out}} \frac{Q_{\text {meas }}^{\mathrm{WT}}-Q_{\mathrm{ref}}^{\mathrm{WT}}}{s} \\ i_{q}= & -\frac{1}{\tau_{\mathrm{inr}}} i_{q}+\frac{1}{\tau_{\mathrm{inr}}} i_{q}^{*} \\ Q_{\mathrm{W}}= & -\frac{3}{2} V_{\mathrm{S}} i_{q} \\ \dot{Q}_{\text {meas }}^{\mathrm{WT}}= & -\frac{1}{\tau_{\mathrm{m}}} Q_{\text {meas }}^{\mathrm{WT}}+\frac{1}{\tau_{\mathrm{m}}} Q_{\mathrm{W}}\end{cases}
$$

where the corresponding variables and parameters are defined in the Nomenclature and Appendix.

\subsubsection{Incremental State-Space Model}

Introduce an auxiliary state variable $Q_{\text {int }}^{\mathrm{WT}}$ defined as,

$$
Q_{\mathrm{int}}^{\mathrm{WT}}:=\frac{Q_{\mathrm{meas}}^{\mathrm{WT}}-Q_{\mathrm{ref}}^{\mathrm{WT}}}{s}
$$

And define $\Delta x_{q}:=\left[\Delta Q_{\mathrm{W}}, \Delta Q_{\text {meas }}^{\mathrm{WT}}, \Delta Q_{\mathrm{int}}^{\mathrm{WT}}\right]^{\mathrm{T}}$ is the state variable vector, $\Delta y_{q}:=\left[\Delta Q_{\mathrm{W}}\right]^{\mathrm{T}}$ is the output variable, and $\Delta u_{q}:=\left[\Delta Q_{\mathrm{ref}}^{\mathrm{WT}}\right]^{\mathrm{T}}$ is the control input. Accordingly, the linearized incremental state-space model regarding the reactive power loop can be expressed as,

$$
\begin{aligned}
& \Delta \dot{x}_{q}=\boldsymbol{A}_{q} \Delta x_{q}+\boldsymbol{B}_{q} \Delta u_{q} \\
& \Delta y_{q}=\boldsymbol{C}_{q} \Delta x_{q}
\end{aligned}
$$


with

$$
\begin{aligned}
\boldsymbol{A}_{q} & =\left[\begin{array}{ccc}
-\frac{1}{\tau_{\mathrm{inr}}} & -\frac{3}{2 \tau_{\mathrm{inr}}} V_{\mathrm{S} 0} K_{\mathrm{p}}^{\mathrm{out}} & -\frac{3}{2 \tau_{\mathrm{inr}}} V_{\mathrm{S} 0} K_{\mathrm{i}}^{\text {out }} \\
\frac{1}{\tau_{\mathrm{m}}} & -\frac{1}{\tau_{\mathrm{m}}} & 0 \\
0 & 1 & 0
\end{array}\right], \\
\boldsymbol{B}_{q} & =\left[\begin{array}{c}
\frac{3}{2 \tau_{\mathrm{inr}}} V_{\mathrm{S} 0} K_{\mathrm{p}}^{\mathrm{out}} \\
0 \\
-1
\end{array}\right], \boldsymbol{C}_{q}=\left[\begin{array}{lll}
1 & 0 & 0
\end{array}\right] .
\end{aligned}
$$

Similarly, the discrete model can be obtained from the continuous state-space model $(8)$ with the sampling time $\Delta \tau_{s}$,

$$
\begin{aligned}
\Delta x_{q}(k+1) & =\boldsymbol{A}_{q}^{\mathrm{d}} \Delta x_{q}(k)+\boldsymbol{B}_{q}^{\mathrm{d}} \Delta u_{q}(k) \\
\Delta y_{q}(k) & =\boldsymbol{C}_{q}^{\mathrm{d}} \Delta x_{q}(k)
\end{aligned}
$$

where

$$
\boldsymbol{A}_{q}^{\mathrm{d}}=e^{\boldsymbol{A}_{q} \Delta \tau_{\mathrm{s}}}, \boldsymbol{B}_{q}^{\mathrm{d}}=\int_{0}^{\Delta \tau_{\mathrm{s}}} e^{\boldsymbol{A}_{q} \tau} \boldsymbol{B}_{q} d \tau, \boldsymbol{C}_{q}^{\mathrm{d}}=\boldsymbol{C}_{q}
$$

\section{D-MPC Based Power Control Design}

The proposed power control scheme includes three parts: 1) distributed synchronization (estimation) of the global reference information $P_{\text {ref }}^{\mathrm{WF}}$ and $V_{\mathrm{POC}} ; 2$ ) distributed estimation of available power of the wind farm $P_{\mathrm{avi}}^{\mathrm{WF}}$; and 3$)$ MPC formulation of the voltage control problem.

\subsection{Synchronization of Global Reference Information}

As mentioned in Section 2, the distributed control scheme is developed based on the sparse and connected communication network. The WT can only exchange information with its neighbors and only a few WTs have directly access to the global information. Thus, the global information cannot be broadcast to each WT in centralized manner. In this context, for $P_{\text {ref }}^{\mathrm{WF}}$ and $V_{\mathrm{POC}}$, a distributed finite-time observer can be adopted to estimate them in a distributed way [25], which is,

$$
\begin{gathered}
\dot{\hat{P}}_{\mathrm{ref}}^{\mathrm{WF}(i)}(t)=\operatorname{sig}\left(\sum_{j=1}^{n} a_{i j}\left(\hat{P}_{\mathrm{ref}}^{\mathrm{WF}(j)}(t)-\hat{P}_{\mathrm{ref}}^{\mathrm{WF}(i)}(t)\right)+g_{i}\left(P_{\mathrm{ref}}^{\mathrm{WF}}(t)-\hat{P}_{\mathrm{ref}}^{\mathrm{WF}(i)}(t)\right)\right)^{\frac{1}{2}} \\
\dot{\hat{V}}_{\mathrm{POC}}^{(i)}(t)=\operatorname{sig}\left(\sum_{j=1}^{n} a_{i j}\left(\hat{V}_{\mathrm{POC}}^{(j)}(t)-\hat{V}_{\mathrm{POC}}^{(i)}(t)\right)+g_{i}\left(V_{\mathrm{POC}}(t)-\hat{V}_{\mathrm{POC}}^{(i)}(t)\right)\right)^{\frac{1}{2}} .
\end{gathered}
$$

According to the theorem in [25], if the communication network is connected, the estimated value $\hat{P}_{\text {ref }}^{\mathrm{WF}(i)}$ and $\hat{V}_{\mathrm{POC}}^{(i)}$ will synchronize to the global references $P_{\mathrm{ref}}^{\mathrm{WF}}$ and $V_{\mathrm{POC}}$ in a finite time, respectively.

\subsection{Distributed Estimation of Total Available Power of the Wind Farm}

Similarly, to estimate $P_{\mathrm{avi}}^{\mathrm{WF}}$ in a distributed way, the average-consensus protocol can achieve it with the sparse and connected communication network. Thus, the distributed estimator can be designed as [26],

$$
\dot{\hat{\bar{P}}}_{\text {avi }}^{\mathrm{WT}(i)}(t)=-\epsilon \sum_{j=1}^{N} a_{i j}\left(\hat{\bar{P}}_{\mathrm{avi}}^{\mathrm{WT}(i)}(t)-\hat{\bar{P}}_{\mathrm{avi}}^{\mathrm{WT}(j)}(t)\right)
$$

where $\epsilon>0$ is the constant gain. According to the theorem in 26, if the communication network is connected, the estimated values will converge to a stable equilibrium that is average of the initial values provided by each WT. The estimation process is executed every several seconds. At the beginning of the process, $\hat{\bar{P}}_{\mathrm{ayi}}^{\mathrm{WT}(i)}$ is initialized with the current available power of WT- $i$. Similarly, if the communication network is connected, $\hat{\bar{P}}_{\text {avi }}^{\mathrm{WT}(i)}$ will definitely converge to $P_{\mathrm{avi}}^{\mathrm{WF}} / N$ in a finite time. Accordingly, each WT can estimate $P_{\mathrm{avi}}^{\mathrm{WF}}$ by,

$$
\hat{P}_{\mathrm{avi}}^{\mathrm{WF}}=N \cdot \hat{\bar{P}}_{\mathrm{avi}}^{\mathrm{WT}(i)} \text {. }
$$




\section{3. $M P C$ Formulation}

In the MPC, the control input is obtained by solving a discrete-time optimal control problem over a given horizon. An optimal control input sequence is produced and only the first control in the sequence is applied. In this paper, the non-cooperative (communication-based) D-MPC is adopted, in which each subsystem (WT) controller anticipates the impact of system interactions only locally and the whole system performance converges to the Nash equilibrium.

For each WT, the control inputs are the active and reactive power commands from the DCPC. In the active power control part, the controller minimizes the fatigue loads represented by fluctuations of low-speed shaft torque $\Delta T_{\mathrm{S}}$ and thrust force $\Delta F_{\mathrm{t}}$ while tracking the power reference $P_{\text {ref }}^{\mathrm{WF}}$. In the reactive power part, the terminal voltage of the WT and voltage at $\mathrm{POC}$ are regulated around 1.0 p.u., which also results in the system active power loss minimization. Besides, the reactive power sharing is also considered. Suppose the prediction and control horizon (steps) are $H_{p}\left(N_{p}=H_{p} / T_{c}\right)$ and $H_{c}\left(N_{c}=H_{c} / T_{c}\right)$, respectively. As known, $N_{p} \geq N_{c}$. From the computational viewpoint, they should be equal, i.e., $N_{p}=N_{c}$, unless the controller is required to consider changes beyond the control horizon.

\subsubsection{Active Power Control}

Supposing $k$ is the current operating point (step), the predictive value and control input of WT- $i(i \in[1, \ldots, N])$ are defined by,

$$
\begin{aligned}
\Delta P_{\mathrm{ref}}^{\mathrm{WT}(i)}(k+l \mid k) & =\Delta u_{p}^{(i)}(k+l \mid k), \\
\Delta T_{\mathrm{s}}^{(i)}(k+l \mid k) & =S_{T_{\mathrm{s}}} \cdot \Delta y_{p}^{(i)}(k+l \mid k), S_{T_{\mathrm{s}}}=[1,0], \\
\Delta F_{\mathrm{t}}^{(i)}(k+l \mid k) & =S_{F_{\mathrm{t}}} \cdot \Delta y_{p}^{(i)}(k+l \mid k), S_{F_{\mathrm{t}}}=[0,1],
\end{aligned}
$$

The MPC formulation of WT- $i$ at step $k$ can be formulated as follows:

$$
\begin{aligned}
\min _{\Delta u_{p}^{(i)}(k \mid k), \ldots, \Delta u_{p}^{(i)}\left(k+N_{p}-1 \mid k\right)} & \sum_{l=1}^{N_{\mathrm{p}}} W_{P}\left(P_{\mathrm{g} 0}^{(i)}+\Delta P_{\mathrm{ref}}^{\mathrm{WT}(i)}(k+l \mid k)-\frac{\hat{P}_{\mathrm{ref}}^{\mathrm{WF}(i)}}{N \cdot \hat{\bar{P}}_{\mathrm{avi}}^{\mathrm{WT}(i)}}\right)^{2} \\
& +\sum_{l=1}^{N_{\mathrm{p}}} W_{T}\left(\Delta T_{\mathrm{s}}^{(i)}(k+l \mid k)\right)^{2}+\sum_{l=1}^{N_{\mathrm{p}}} W_{F}\left(\Delta F_{\mathrm{t}}^{(i)}(k+l \mid k)\right)^{2}
\end{aligned}
$$

subject to

$$
\begin{aligned}
\Delta x_{p}^{(i)}(k+l+1 \mid k) & =\boldsymbol{A}_{p}^{\mathrm{d}(i)} \Delta x_{p}(k+l \mid k)+\boldsymbol{B}_{p}^{\mathrm{d}(i)} \Delta u_{p}(k+l \mid k)+\boldsymbol{E}_{p}^{\mathrm{d}(i)}(k+l \mid k), \\
\Delta y_{p}^{(i)}(k+l \mid k) & =\boldsymbol{C}_{p}^{\mathrm{d}(i)} \Delta x_{p}(k+l \mid k)+\boldsymbol{D}_{p}^{\mathrm{d}(i)} \Delta u_{p}(k+l-1 \mid k), \\
0 & \leq P_{\mathrm{g} 0}^{(i)}+\Delta u_{p}^{(i)}(k+l \mid k) \leq P_{\mathrm{avi}}^{\mathrm{WT}(i)}
\end{aligned}
$$

where the first term in the cost function is used as the soft constraint of the power reference tracking. The second term and third term are used to penalize the fatigue loads of the WT. $W_{P}, W_{T}$, and $W_{F}$ are the weighting factors which penalize for power tracking, shaft torque and thrust force, respectively.

\subsubsection{Reactive Power Control}

By defining the predicted power output vectors, senstivity vector and control input vector,

$$
\begin{aligned}
\Delta Y_{p}^{(i)}(k+l \mid k)= & {\left[a_{i 1} \Delta P_{\mathrm{ref}}^{\mathrm{WT}(1)}(k+l \mid k-1), \ldots, a_{i(i-1)} \Delta P_{\mathrm{ref}}^{\mathrm{WT}(i-1)}(k+l \mid k-1),\right.} \\
& \left.\Delta P_{\mathrm{ref}}^{\mathrm{WT}(i)}(k+l \mid k), a_{i(i+1)} \Delta P_{\mathrm{ref}}^{\mathrm{WT}(i+1)}(k+l \mid k-1), \ldots, a_{i N} \Delta P_{\mathrm{ref}}^{\mathrm{WT}(N)}(k+l \mid k-1)\right]^{\mathrm{T}}, \\
\Delta Y_{q}^{(i)}(k+l \mid k)= & {\left[a_{i 1} \Delta y_{q}^{(1)}(k+l \mid k-1), \ldots, a_{i(i-1)} \Delta y_{q}^{(i-1)}(k+l \mid k-1)\right.} \\
& \left.\Delta y_{q}^{(i)}(k+l \mid k), a_{i(i+1)} \Delta y_{q}^{(i+1)}(k+l \mid k-1), \ldots, a_{i N} \Delta y_{q}^{(N)}(k+l \mid k-1)\right]^{\mathrm{T}}, \\
S_{V_{\mathrm{POC}}}^{P(i)}= & {\left[\frac{\partial V_{\mathrm{POC}}}{P_{\mathrm{W}_{1}}}, \ldots, \frac{\partial V_{\mathrm{POC}}}{P_{\mathrm{W}_{i-1}}}, \frac{\partial V_{\mathrm{POC}}}{P_{\mathrm{W}_{i}}}, \frac{\partial V_{\mathrm{POC}}}{P_{\mathrm{W}_{i+1}}}, \ldots, \frac{\partial V_{\mathrm{POC}}}{P_{\mathrm{W}_{N}}}\right], } \\
S_{V_{\mathrm{POC}}}^{Q(i)}= & {\left[\frac{\partial V_{\mathrm{POC}}}{Q_{\mathrm{W}_{1}}}, \ldots, \frac{\partial V_{\mathrm{POC}}}{Q_{\mathrm{W}_{i-1}}}, \frac{\partial V_{\mathrm{POC}}}{Q_{\mathrm{W}}}, \frac{\partial V_{\mathrm{POC}}}{Q_{\mathrm{W}_{i+1}}}, \ldots, \frac{\partial V_{\mathrm{POC}}}{Q_{\mathrm{W}_{N}}}\right], }
\end{aligned}
$$




$$
\begin{aligned}
& S_{V_{\mathrm{W}}}^{P(i)}=\left[\frac{\partial V_{\mathrm{W}_{i}}}{P_{\mathrm{W}_{1}}}, \ldots, \frac{\partial V_{\mathrm{W}_{i}}}{P_{\mathrm{W}_{i-1}}}, \frac{\partial V_{\mathrm{W}_{i}}}{P_{\mathrm{W}_{i}}}, \frac{\partial V_{\mathrm{W}_{i}}}{P_{\mathrm{W}_{i+1}}}, \ldots, \frac{\partial V_{\mathrm{W}_{i}}}{P_{\mathrm{W}_{N}}}\right], \\
& S_{V_{\mathrm{W}}}^{Q(i)}=\left[\frac{\partial V_{\mathrm{W}_{i}}}{Q_{\mathrm{W}_{1}}}, \ldots, \frac{\partial V_{\mathrm{W}_{i}}}{Q_{\mathrm{W}_{i-1}}}, \frac{\partial V_{\mathrm{W}_{i}}}{Q_{\mathrm{W}_{i}}}, \frac{\partial V_{\mathrm{W}}}{Q_{\mathrm{W}_{i+1}}}, \ldots, \frac{\partial V_{\mathrm{W}_{i}}}{Q_{\mathrm{W}_{N}}}\right] .
\end{aligned}
$$

where the variables $\Delta P_{\mathrm{ref}}^{\mathrm{WT}(j)}(k+l \mid k-1), \Delta y_{q}^{(j)}(k+l \mid k-1)$ are the predicted information at step $k+l$ computed at step $k-1$, which are exchanged from other neighboring WTs. If WT- $i$ and WT- $j$ have direct communication link which means they can exchange the above information, $a_{i j}=1$, otherwise $a_{i j}=0$. Thus, the predicted voltages based on the first-order Taylor approximation can be expressed by,

$$
\begin{aligned}
\Delta V_{\mathrm{POC}}^{(i)}(k+l \mid k) & =S_{V_{\mathrm{POC}}}^{P(i)} \cdot \Delta Y_{p}^{(i)}+S_{V_{\mathrm{POC}}}^{Q(i)} \cdot \Delta Y_{q}^{(i)}(k+l \mid k), \\
\Delta V_{\mathrm{W}_{i}}(k+l \mid k) & =S_{V_{\mathrm{W}}}^{P(i)} \cdot \Delta Y_{p}^{(i)}+S_{V_{\mathrm{W}}}^{Q(i)} \cdot \Delta Y_{q}^{(i)}(k+l \mid k) .
\end{aligned}
$$

Then, the optimal reactive power control problem can be formulated as,

$$
\begin{aligned}
\min _{\Delta u_{q}^{(i)}(k \mid k), \ldots, \Delta u_{q}^{(i)}\left(k+N_{p}-1 \mid k\right)} & \sum_{l=1}^{N_{p}} W_{\mathrm{POC}}\left(\Delta V_{\mathrm{POC}}^{(i)}(k+l \mid k)+\varepsilon \cdot\left(\hat{V}_{\mathrm{POC}}^{(i)}-V_{\mathrm{ref}}\right)\right)^{2} \\
& +\sum_{l=1}^{N_{p}} W_{\mathrm{W}}\left(\Delta V_{\mathrm{W}_{i}}(k+l \mid k)+\varepsilon \cdot\left(V_{\mathrm{W}_{i}}^{0}-V_{\mathrm{ref}}\right)\right)^{2} \\
& +\sum_{l=1}^{N_{p}} \sum_{j=1}^{N} a_{i j} W_{Q}\left(\frac{\Delta y_{q}^{(i)}(k+l \mid k)+Q_{\mathrm{W}_{i} 0}}{\bar{Q}_{\mathrm{W}, i}}-\frac{Q_{\mathrm{W}_{j}}(k+l \mid k-1)}{\bar{Q}_{\mathrm{W}, j}}\right)^{2}
\end{aligned}
$$

subject to

$$
\begin{aligned}
\Delta x_{q}^{(i)}(k+l+1 \mid k) & =\boldsymbol{A}_{q}^{\mathrm{d}(i)} \Delta x_{q}^{(i)}(k+l \mid k)+\boldsymbol{B}_{q}^{\mathrm{d}(i)} \Delta u_{q}^{(i)}(k+l \mid k), \\
\Delta y_{q}^{(i)}(k+l \mid k) & =C_{q}^{(i)} \Delta x_{q}^{(i)}(k+l \mid k), \\
\underline{Q}_{\mathrm{W}_{i}}(k+l \mid k) & \leq Q_{\mathrm{W}_{i} 0}+\Delta y_{q}^{i}(k+l \mid k) \leq \bar{Q}_{\mathrm{W}_{i}}(k+l \mid k) .
\end{aligned}
$$

The first term and second term in the cost function are used to penalize the voltage deviations. The third term is used to penalize the differences of reactive power sharing among WTs. The ratio $Q_{\mathrm{W}_{j}}(k+l \mid k-1) / \bar{Q}_{\mathrm{W}, j}$ is the predicted reactive power utilization of WT- $j$ at step $k+l$ computed at step $k-1$, which is exchanged from the WT- $j$. $W_{\mathrm{POC}}, W_{\mathrm{W}}$ and $W_{Q}$ are the weighting factors for the voltage at the POC, WT terminal voltage and reactive power sharing, respectively. $\varepsilon>0$ denotes the constant gain which can be used to adjust the control performances. The reactive power limits of a WT depend on the terminal voltage and active power output. As shown in Fig. 6 the relationship can be expressed as the lookup table and the values of $\underline{Q}_{\mathrm{W}}$ and $\bar{Q}_{\mathrm{W}}$ can be obtained based on the interpolation.

The presented MPC problems can be transformed into a standard Quadratic Programming (QP) problem and efficiently solved by commercial QP solvers in milliseconds.

\section{Case Study}

In this section, a wind farm with ten $5 \mathrm{MW}$ WTs with the communication network as illustrated in Fig. 7 is used to validate the proposed control scheme. The WTs are connected by $33 \mathrm{kV}$ collector cables and the wind farm is connected to the external grid through a $110 \mathrm{kV} / 33 \mathrm{kV}$ transformer. The wind farm is connected to the IEEE-14 bus test system at Bus 05 (see Fig. 8). WT-01 is selected as the leader of all WTs which has direct access to the global reference information. The proposed control scheme along with the solution method is implemented in the MATLAB/SIMULINK on a PC with an Intel(R) Core(TM) i7-6700HQ CPU @2.60GHz processor and 8 GB RAM, running Windows 10. The distributed controller was implemented using a MATLAB-function block with a packaging triggered subsystem. The wind condition modeling of the wind farm considering the wake effects and turbulences was generated using the SimWindFarm Toolbox 24. More detailed WT parameters can be found in the Appendix.

The available power estimation is executed every $10 \mathrm{~s}$ and the sensitivity coefficients are updated every $120 \mathrm{~s}$. The control period of the D-MPC is set as $1 \mathrm{~s}$ and $N_{p}=N_{c}=5$. The simulation results of the proposed distributed control 


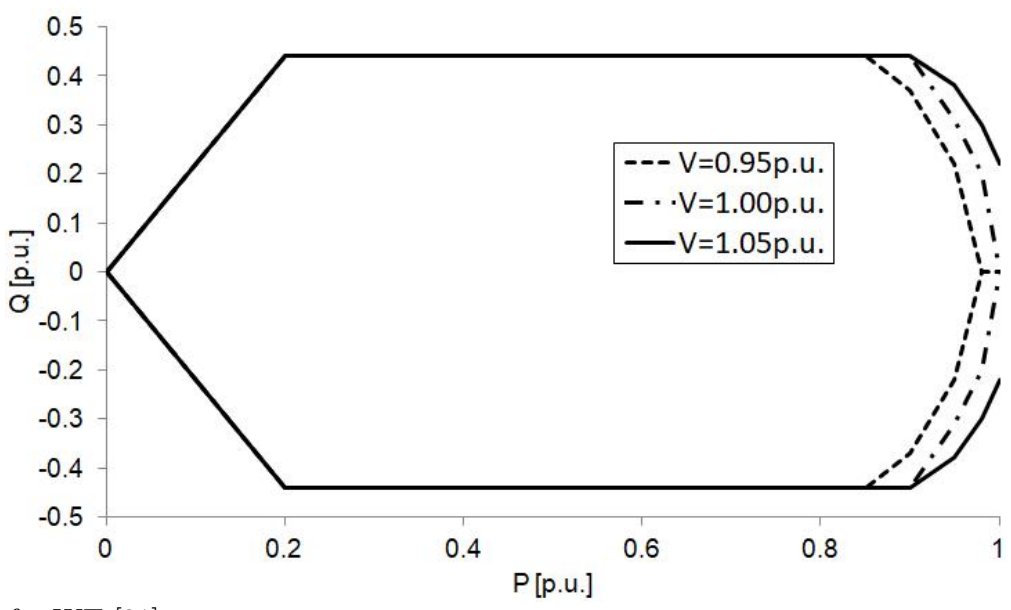

Figure 6: Reactive power limit of a WT [21].

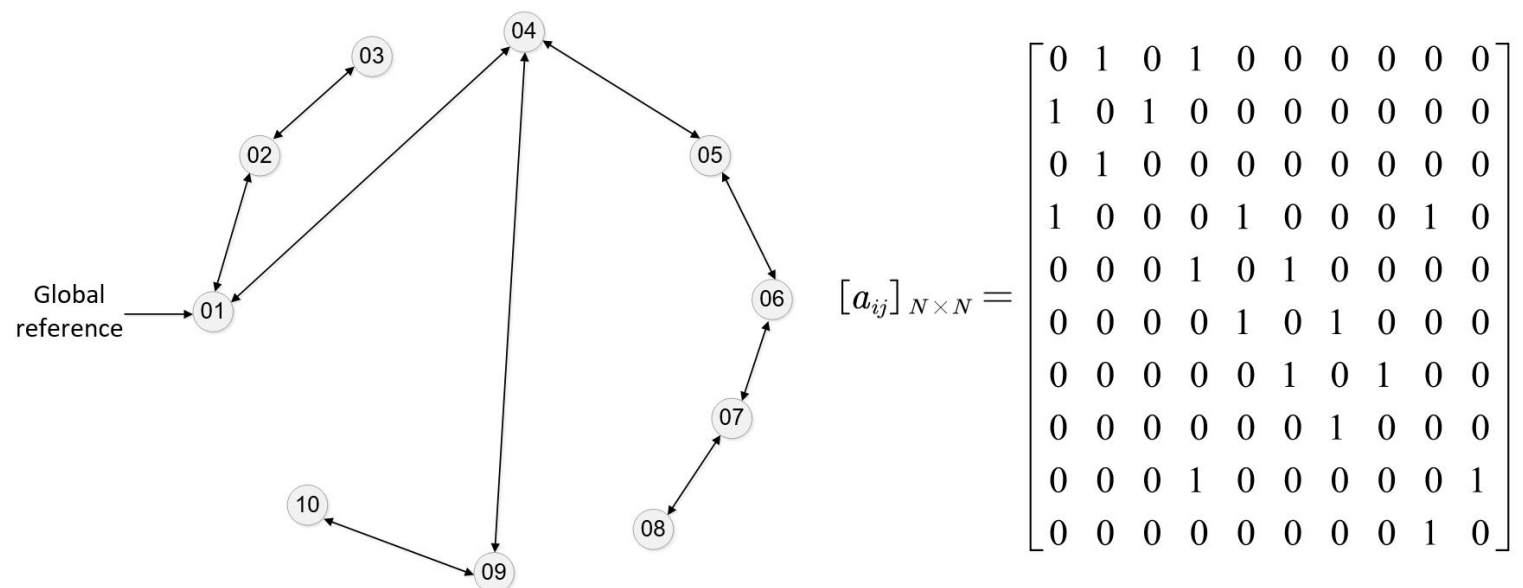

Figure 7: Communication network topology.

scheme are compared with the conventional centralized control. For the active power control, the proportional dispatch strategy is used according to the available power is given as,

$$
P_{\mathrm{ref}}^{\mathrm{WT}(i)}=\frac{P_{\mathrm{ref}}^{\mathrm{WF}} * P_{\mathrm{avi}}^{\mathrm{WT}(i)}}{P_{\mathrm{avi}}^{\mathrm{WF}}}
$$

For reactive power control, the conventional centralized optimal voltage control [12] is adopted, which solves the following optimization problem at each control step,

$$
\begin{gathered}
\min _{Q_{W_{1}}, \ldots, Q_{W_{N}}} W_{\mathrm{POC}}\left(V_{\mathrm{POC}}-V_{\mathrm{ref}}\right)^{2}+\sum_{i} W_{\mathrm{W}}\left(V_{\mathrm{W}_{i}}-V_{\mathrm{ref}}\right)^{2}+W_{Q} \sum_{i, j}\left(\frac{Q_{\mathrm{W}_{i}}}{\bar{Q}_{W_{i}}}-\frac{Q_{\mathrm{W}_{j}}}{\bar{Q}_{W_{j}}}\right)^{2} \\
\text { subject to } \\
\underline{Q}_{W} \leq Q_{W} \leq \bar{Q}_{W} \\
V_{\mathrm{POC}}=V_{\mathrm{POC} 0}+\frac{\partial V_{\mathrm{POC}}}{\partial Q_{W_{1}}} \Delta Q_{W_{1}}+\cdots+\frac{\partial V_{\mathrm{POC}}}{\partial Q_{W_{N}}} \Delta Q_{W_{N}}, \\
V_{\mathrm{W}}=V_{\mathrm{W} 0}+\frac{\partial V_{\mathrm{W}}}{\partial Q_{W_{1}}} \Delta Q_{W_{1}}+\cdots+\frac{\partial V_{\mathrm{W}}}{\partial Q_{W_{N}}} \Delta Q_{W_{N}} .
\end{gathered}
$$

The sampling time of the centralized controller is designed as $1 \mathrm{~s}$.

\subsection{Performance of the Estimator and Observer}

The total simulation time is $600 \mathrm{~s}$. The power reference and available power of the wind farm are shown in Fig. 9 The power demand changes from $20 \mathrm{MW}$ to $30 \mathrm{MW}$ at $t=200 \mathrm{~s}$ and from $30 \mathrm{MW}$ to $25 \mathrm{MW}$ at $t=470 \mathrm{~s}$. 


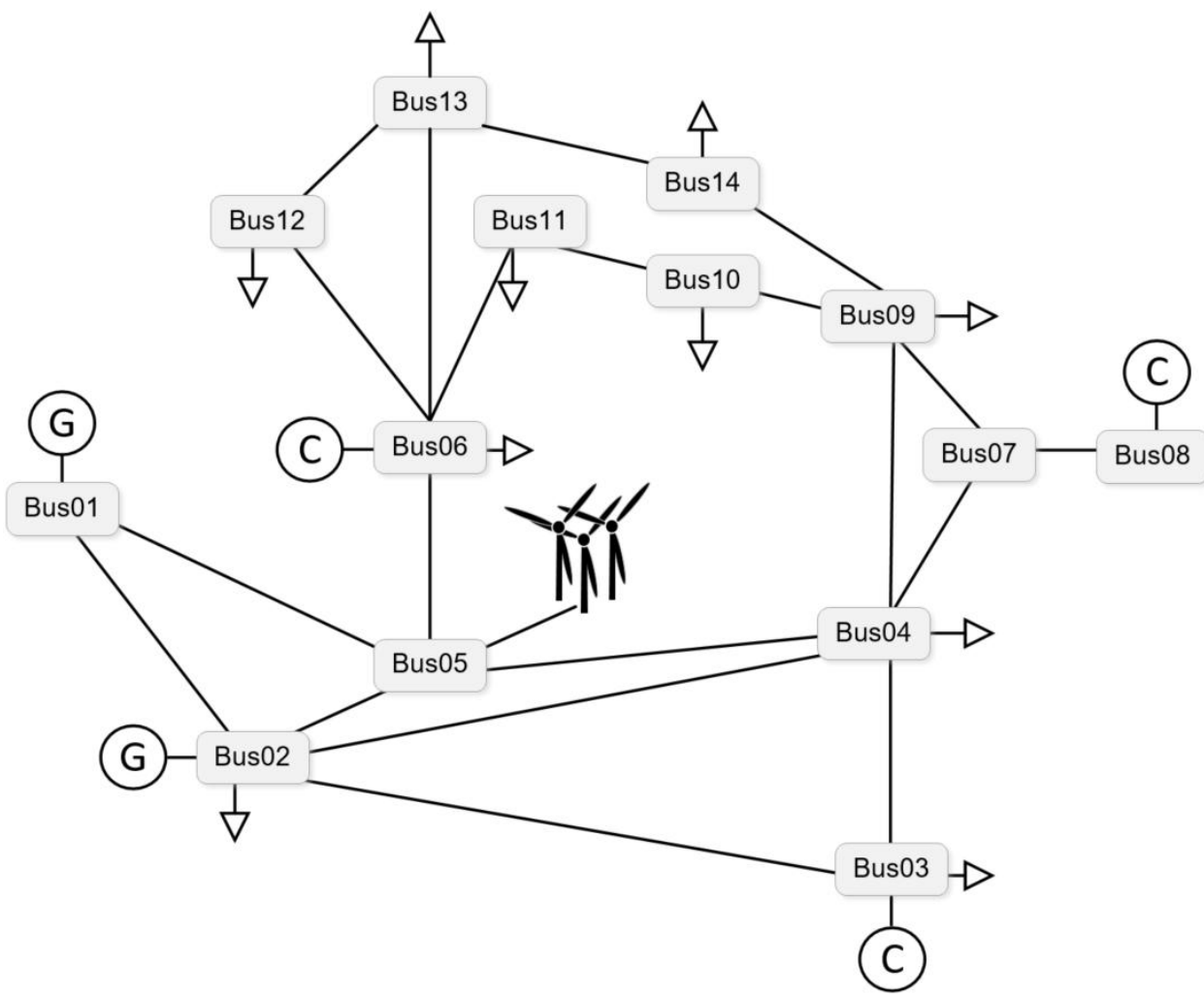

Figure 8: IEEE-14 bus system with the wind farm.

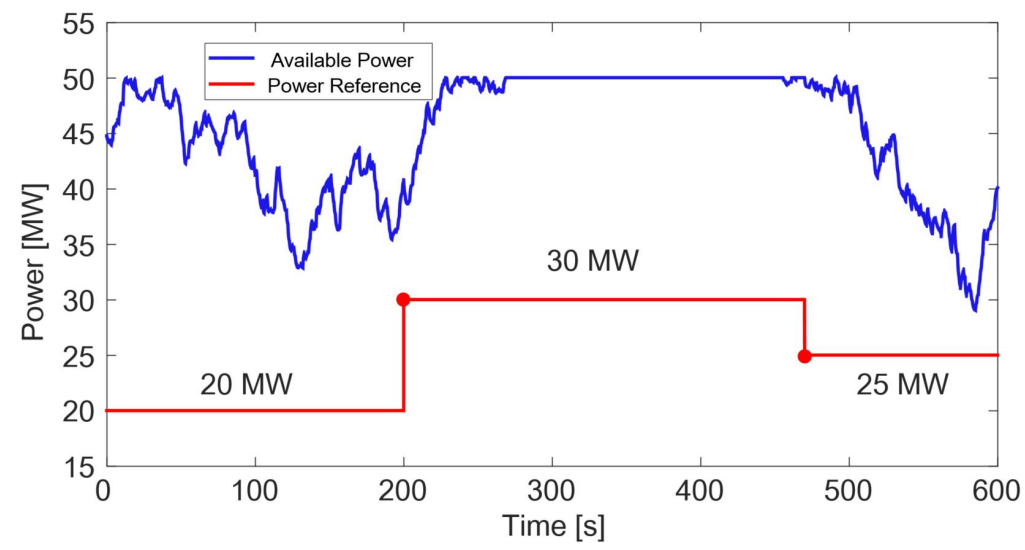

Figure 9: Power reference and available power of the wind farm.

The performances of the estimator for the total available power of the wind farm and the observer for wind farm power reference are presented in this subsection. The estimated available power of the wind farm is shown in Fig. 10, It can be observed that all the estimators can fast converge to the actual value within about $1 \mathrm{~s}$ after every updated point (every 10 s). The synchronization of the wind farm power reference is shown in Fig. 11. As can be seen, the distributed observers can fast track the variations of the power reference, implying the global information can be effectively synchronized in the wind farm.

\subsection{Power Tracking and Fatigue Loads Reduction}

\subsubsection{Power Tracking}

To avoid sharp power variations of WTs, the (estimated) wind farm power reference is sent to the distributed controller (after the observer) or central controller through a first-order low-pass filter with the time constant of $10 \mathrm{~s}$. The power reference tracking performance of the proposed scheme is illustrated in Fig. 12. It can be seen that the centralized 


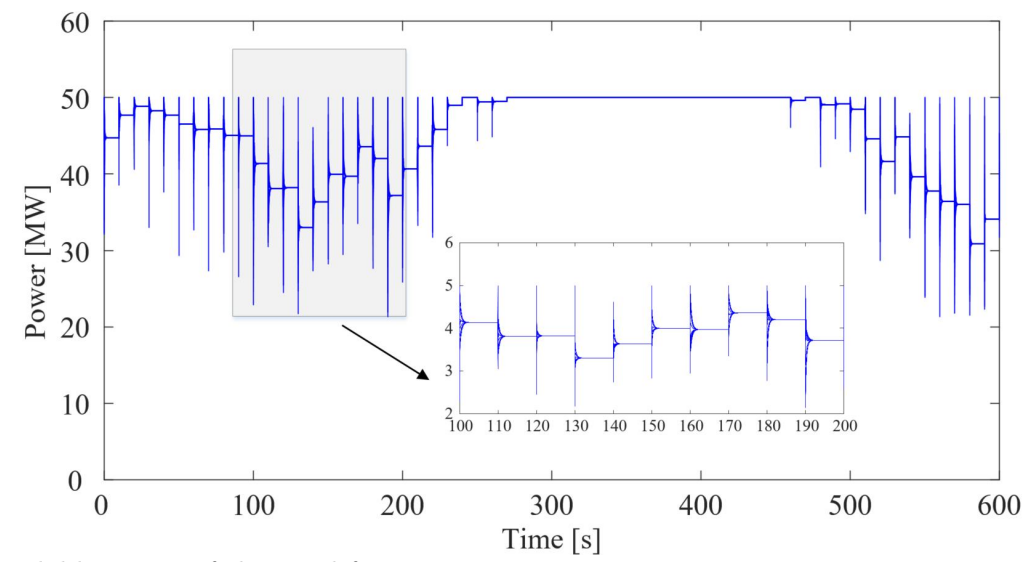

Figure 10: Estimation of the available power of the wind farm.

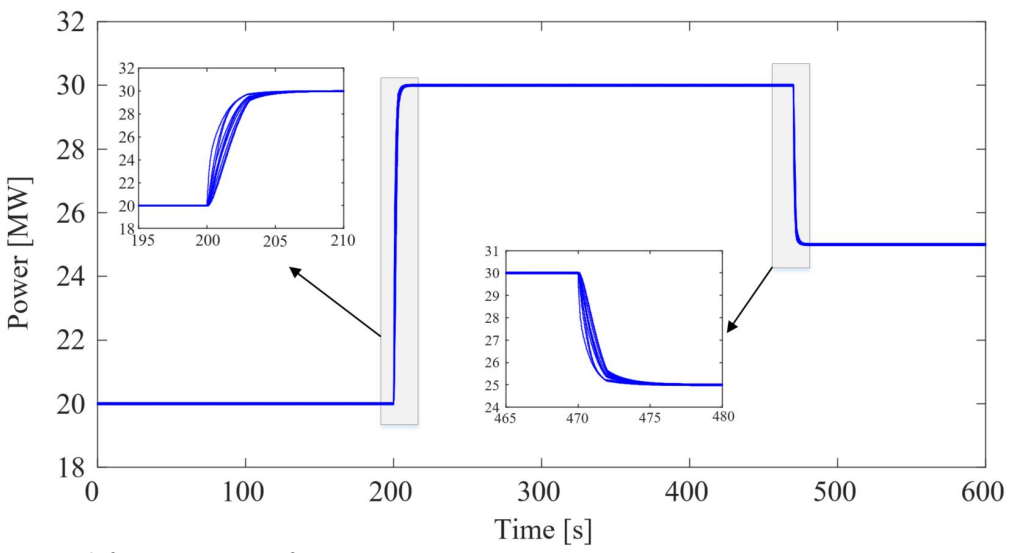

Figure 11: Synchronization of the wind farm power reference.

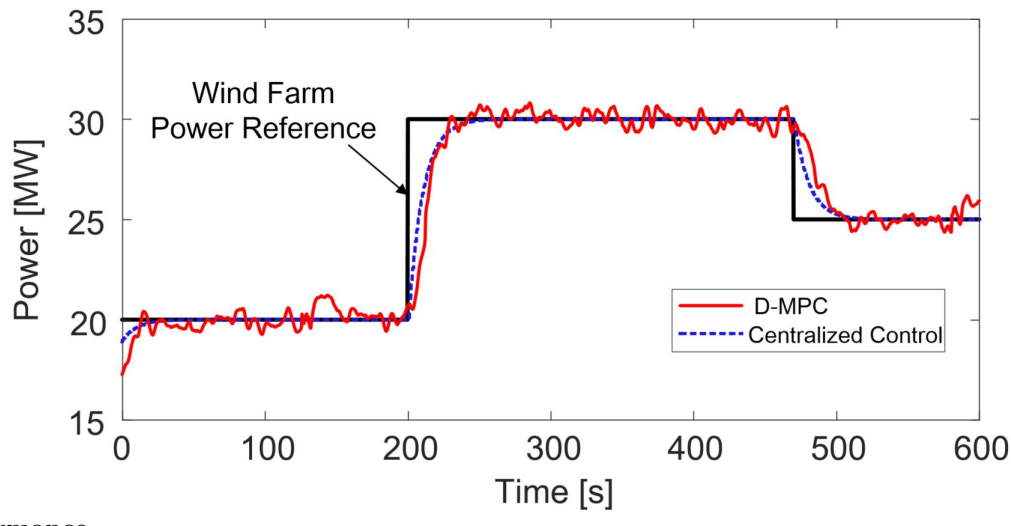

Figure 12: Power tracking peformance.

controller can precisely track the power reference of the wind farm. The D-MPC can also regulate the output power within small deviations, implying the power tracking performance of the proposed scheme is acceptable.

\subsubsection{Fatigue Loads Reduction}

WT-04 is used as an example to validate the fatigue loads reduction performance. The shaft torque and thrust force of WT-04 are shown in Fig. 13 and Fig. 14, respectively. Compared with the centralized control, the variations of $T_{\mathrm{s}}$ and $F_{\mathrm{t}}$ are reduced with D-MPC, implying the less fatigue loads experienced by WTs. The standard deviations $T_{\mathrm{s}}$ and $F_{\mathrm{t}}$ for all WTs are listed in Table 1. For $T_{\mathrm{s}}$, the standard deviations are reduced by $5 \%-8 \%$ and for $F_{\mathrm{t}}$, they are $27 \%-59 \%$. 


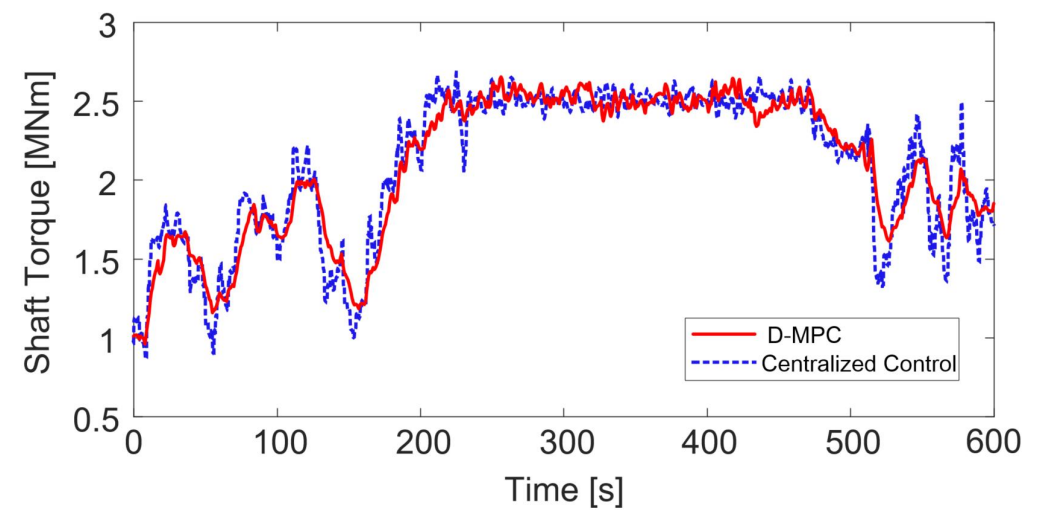

Figure 13: Shaft torque $T_{\mathrm{s}}$ of WT-04.

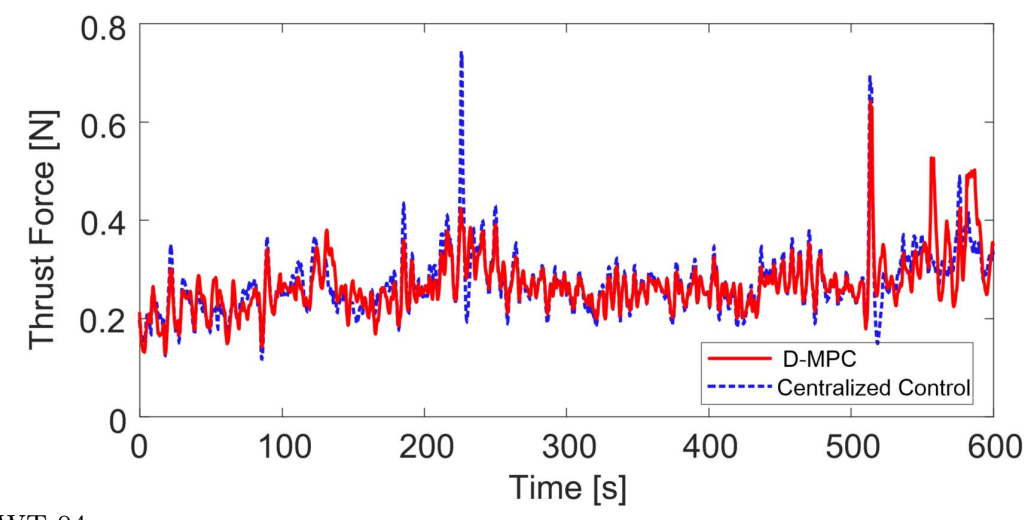

Figure 14: Thrust force $F_{\mathrm{t}}$ of WT-04.

Table 1

Standard deviations of shaft torque $\sigma\left(T_{\mathrm{S}}\right)$ and thrust force $\sigma\left(F_{\mathrm{t}}\right)$

\begin{tabular}{c|c|c|c|c}
\hline \multirow{2}{*}{ Wind Turbine } & \multicolumn{2}{|c|}{$\sigma\left(T_{\mathrm{s}}\right)[\mathrm{MNm}]$} & \multicolumn{2}{c}{$\sigma\left(F_{\mathrm{t}}\right)[\mathrm{MN}]$} \\
\cline { 2 - 5 } & D-MPC & Centralized Control & D-MPC & Centralized Control \\
\hline WT-01 & $0.4401(8.0 \%)$ & 0.4781 & $0.0351(37.8 \%)$ & 0.0565 \\
\hline WT-02 & $0.4050(6.1 \%)$ & 0.4313 & $0.0383(36.1 \%)$ & 0.0600 \\
\hline WT-03 & $0.4523(5.9 \%)$ & 0.4805 & $0.0348(38.7 \%)$ & 0.0568 \\
\hline WT-04 & $0.4521(3.3 \%)$ & 0.4674 & $0.0358(34.5 \%)$ & 0.0546 \\
\hline WT-05 & $0.5074(5.9 \%)$ & 0.4793 & $0.0308(58.5 \%)$ & 0.0741 \\
\hline WT-06 & $0.4046(5.7 \%)$ & 0.4290 & $0.0329(27.3 \%)$ & 0.0453 \\
\hline WT-07 & $0.3885(6.3 \%)$ & 0.4144 & $0.0386(31.5 \%)$ & 0.0564 \\
\hline WT-08 & $0.4197(5.9 \%)$ & 0.4461 & $0.0378(26.6 \%)$ & 0.0515 \\
\hline WT-09 & $0.3647(4.8 \%)$ & 0.3830 & $0.0331(35.7 \%)$ & 0.0515 \\
\hline WT-10 & $0.4613(5.3 \%)$ & 0.4871 & $0.0337(42.1 \%)$ & 0.0582 \\
\hline
\end{tabular}

\subsection{Voltage Regulation}

In this subsection, the voltage control performance is evaluated. According to experimental studies in [27, the minimal information update interval in IEEE 802.11 is in the order of $10 \mathrm{~ms}$. For the commonly used fiber optical, the time delay might be in the range of several milliseconds (less than $1.5 \mathrm{~ms}$ for $40 \mathrm{~km}$ ) [28]. They both can be used for distributed control. Thus, to further illustrate the potential benefits of D-MPC for voltage control, the sampling time of the D-MPC is reduced to $0.2 \mathrm{~s}$. The voltage reference $V_{\text {ref }}$ is set as 1.0 p.u.. A reactive power load is suddenly added to Bus06 at $t=120 \mathrm{~s}$ and removed at $t=420 \mathrm{~s}$. Fig. 15 shows the voltage at the POC. WT-04 (closest bus along the feeder) and WT-08 (furthest bus along the feeder) are selected as the representative WTs. Their terminal voltages are shown in Figs. 16 and 17 
Figure 15: Voltage at POC.
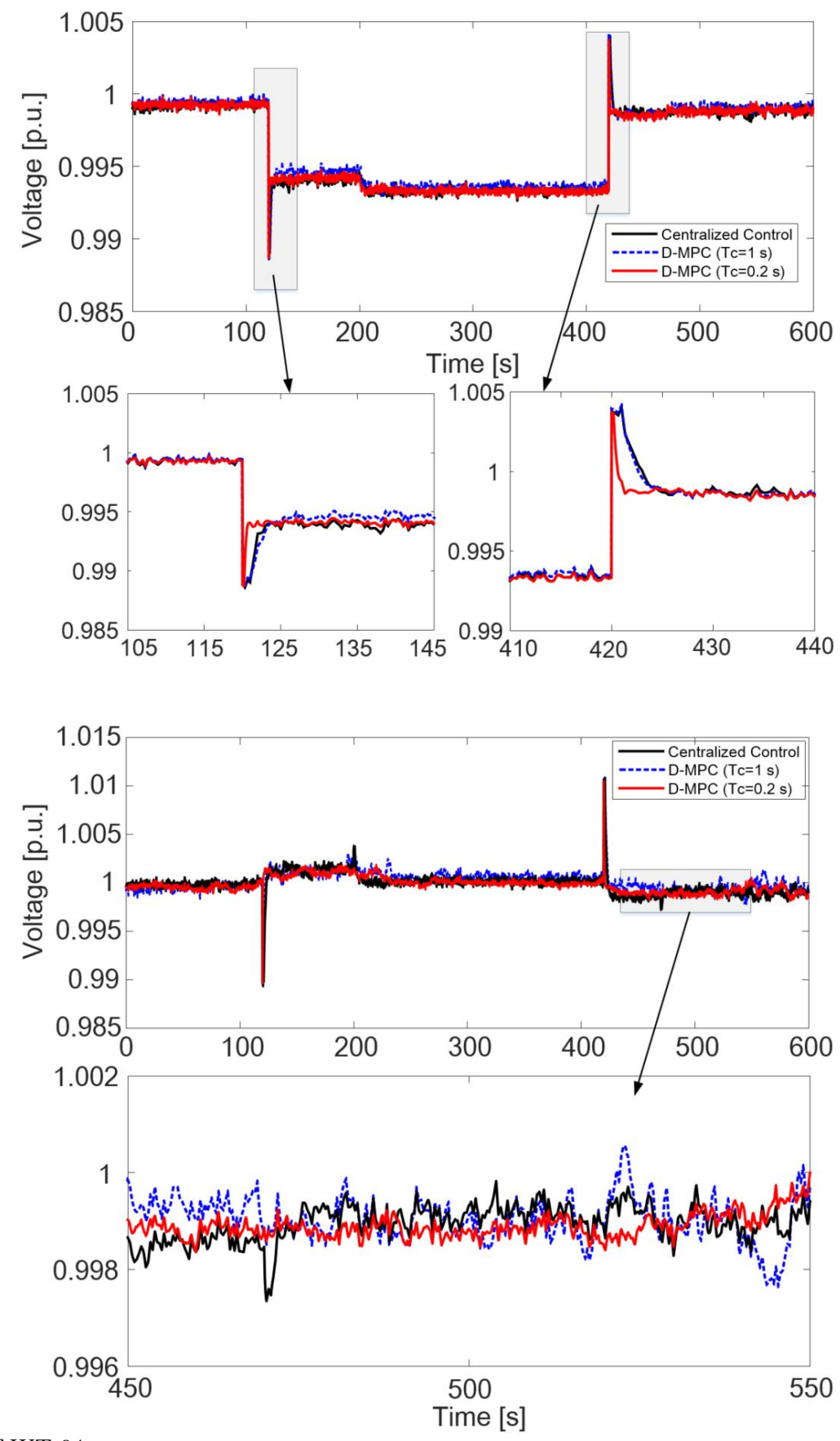

Figure 16: Terminal voltage of WT-04.

As shown in Fig. 15, both the centralized control and D-MPC can efficiently regulate the $V_{\mathrm{POC}}$ within the feasible range of $0.99 \sim 1.01$ p.u., implying the good voltage regulation performance. After the disturbances at $t=120 \mathrm{~s}, V_{\mathrm{POC}}$ suddenly falls to 0.99 p.u. and then it recovers to 0.995 p.u. due to the reactive power support of WTs. After the disturbance at $t=420 \mathrm{~s}, V_{\mathrm{POC}}$ suddenly exceeds 1.004 p.u., and then it recovers close to 1.0 p.u.. And as can be seen, the overall performances of the D-MPC and the centralized control, which have the same control period $1 \mathrm{~s}$, are similar. However, if the control period of the D-MPC can be shortened to $0.2 \mathrm{~s}$, the D-MPC can significantly improve the voltage recovery performance, which shows the advantages of the D-MPC. Similarly, as can be seen from Figs. 16 and 17 , the terminal voltages of WTs, including the furthest WT along the feeder, i.e. WT-08, can be effectively controlled around 1.0 p.u.. Compared with the centralized control, the D-MPC with shorter control period shows better control performance. 


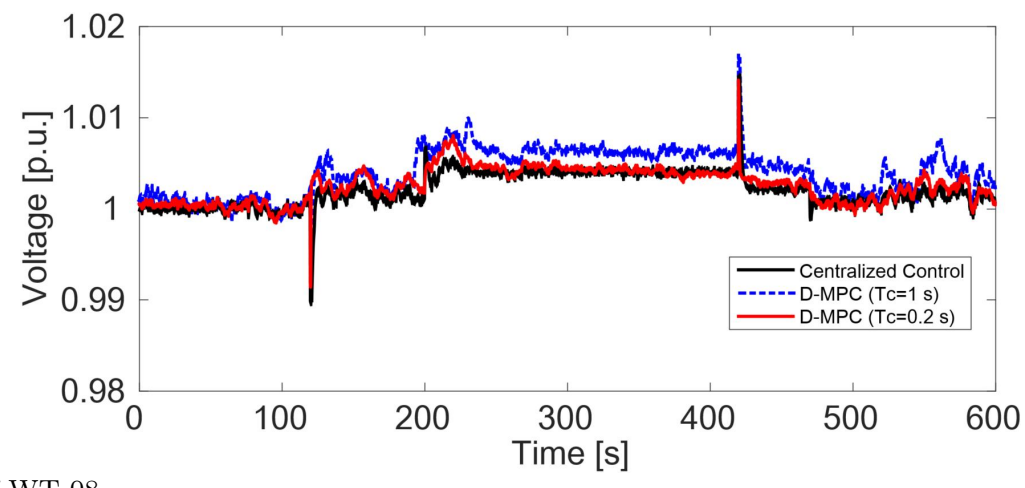

Figure 17: Terminal voltage of WT-08.

\subsection{Comparison of the Coordinated and Separated Control}

In this subsection, the comparison of the coordinated (proposed in this paper) and the conventional separated active power and reactive control of a wind farm is presented. The simulation time is $100 \mathrm{~s}$. It can be seen from Figs. 18 and 19 that both the coordinated D-MPC and separated D-MPC can effectively regulate the voltage within the feasible range. Compared with the separated D-MPC, the coordinated D-MPC can better control the voltage with smaller deviations and fluctuations, which further demonstrates the advantages of the proposed control scheme.

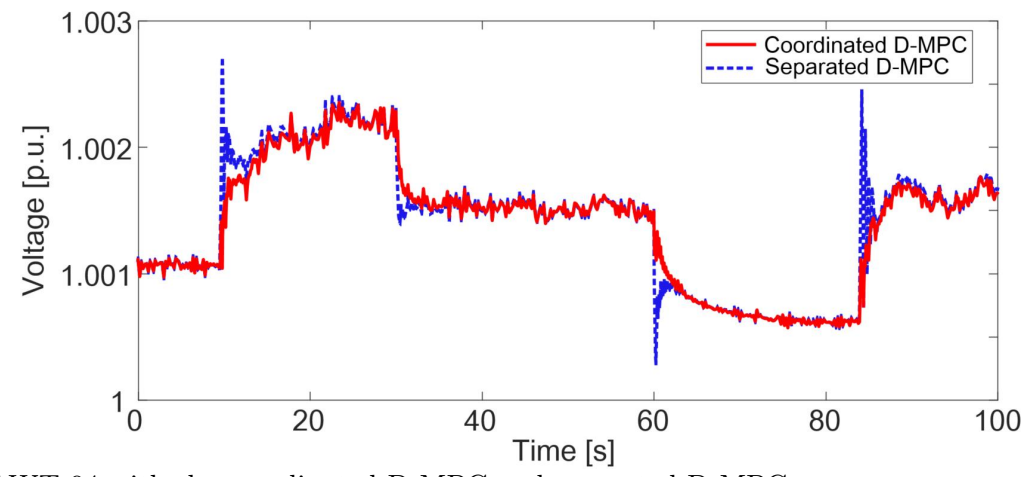

Figure 18: Terminal voltage of WT-04 with the coordinated D-MPC and separated D-MPC.

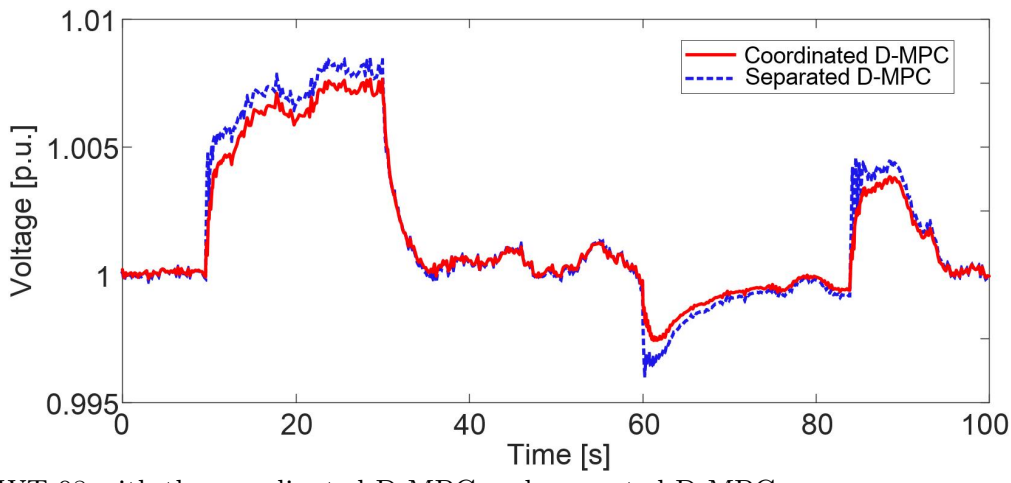

Figure 19: Terminal voltage of WT-08 with the coordinated D-MPC and separated D-MPC.

\section{Conclusion}

This paper proposes a distributed coordinated active and reactive power control scheme for wind farms based on the MPC, in which the distributed reactive/voltage control of wind farms is achieved and coordinated with the active power control. The simulation results validate that the proposed control scheme can effectively reduce the fatigue loads experienced by WTs while tracking the wind farm power reference. And it can regulate the voltages within the feasible 
range. By shortening the control period, the control performance of the D-MPC can be significantly improved and better than the centralized control. Compared with the separated active and reactive power control, the proposed coordinated control can better regulate the voltages with smaller fluctuations and deviations by taking into account the impact of active power variations on voltages. Besides, since the distributed control scheme is center-free and only requires sparse communication network, it could be helpful to significantly reduce the costs for large-scale wind farms, implying better scalability and economic performances.

\section{Acknowledgment}

This work is supported in part by the National Key Research and Development Program of China (2016YFB0900603) and in part by the China Scholarship Council (CSC).

\section{Appendix}

The parameters of WTs and the wind farm are presented in the Tables 2 and 3 .

\section{Table 2}

Parameters of wind farm collector system.

\begin{tabular}{ll}
\hline Unit & Parameters \\
\hline $33 \mathrm{kV}$ Cable & $R=0.0975 \Omega / \mathrm{km}, L=0.38 \mathrm{mH} / \mathrm{km}, C=0.24 \mu \mathrm{F} / \mathrm{km}$ \\
$33 \mathrm{kV} / 110 \mathrm{kV}$ Transformer & $S_{N}=50 \mathrm{MVA}, R=0.002$ p.u., $X=0.12$ p.u. \\
\hline
\end{tabular}

Table 3

Parameters of a 5-MW wind turbine model.

\begin{tabular}{lll}
\hline Symbol & Description & Value \\
\hline$\eta$ & Gearbox ratio & 97 \\
$R$ & Rotor radius $[\mathrm{m}]$ & 63 \\
$J_{\mathrm{r}}$ & Rotor inertia $\left[\mathrm{kg} \cdot \mathrm{m}^{2}\right]$ & $3.544 \cdot 10^{7}$ \\
$J_{\mathrm{g}}$ & Generator inertia $\left[\mathrm{kg} \cdot \mathrm{m}^{2}\right]$ & 534.116 \\
$\omega_{g}^{\text {rated }}$ & Rated generator speed $[\mathrm{rad} / \mathrm{s}]$ & 122.9096 \\
$\mu$ & Generator efficiency & 0.944 \\
$\rho$ & Air density & 1.2231 \\
$K_{\mathrm{p}}^{\theta}$ & Proportional gain of the pitch control & 0.1965 \\
$K_{\mathrm{i}}^{\theta}$ & Integral gain of the pitch control & 0.0842 \\
$K_{0}$ & Gain scheduling coefficient & 1 \\
$K_{1}$ & Gain scheduling coefficient & 1.9412 \\
$K_{\mathrm{p}}^{\text {out }}$ & Proportional gain of the converter control & 25 \\
$K_{\mathrm{i}}^{\text {out }}$ & Integral gain of the converter control & 5000 \\
$\tau_{\mathrm{m}}$ & time constant of low-pass filter $[\mathrm{ms}]$ & 10 \\
$\tau_{\mathrm{inr}}$ & time constant of low-pass filter $[\mathrm{ms}]$ & 5 \\
\hline
\end{tabular}

\section{References}

[1] L. Xu, L. Yao, and C. Sasse, "Grid integration of large DFIG-based wind farms using VSC transmission," IEEE Trans. Power Syst., vol. 22, no. 3, pp. 976-984, Aug. 2007.

[2] L. Yang, Z. Xu, J. Østergaard, Z. Y. Dong, and K. P. Wong, "Advanced control strategy of DFIG wind turbines for power system fault ride through," IEEE Trans. Power Syst., vol. 27, no. 2, pp. 713-722, May 2012.

[3] Y. Wang, J. Meng, X. Zhang, and L. Xu, "Control of PMSG-based wind turbines for system inertial response and power oscillation damping," IEEE Trans. Sustain. Energy, vol. 6, no. 2, pp. 565-574, Apr. 2015.

[4] B. R. Karthikeya and R. J. Schutt, "Overview of wind park control strategies," IEEE Trans. on Sustain. Energy, vol. 5, no. 2, pp. 416-422, Apr. 2014. 
[5] P. E. Sørensen, A. D. Hansen, F. Iov, F. Blaabjerg, and M. H. Donovan, "Wind farm models and control strategies," Ris $\varnothing$ Nat. Lab., Denmark, Roskilde, Tech. Rep. Ris $\varnothing-4-1464$, Aug. 2005.

[6] X. Guan and G. M. van der Molen, Control strategy review and specification(Part 1), 2009 [Online]. Available: http://ictaeolus.eu/pub/ISC/_300409_deliverable_D3-1_0001(1)_PU.pdf.

[7] J. R. Kristoffersen and P. Christiansen, "Horns Rev offshore wind-farm: its main controller and remote control system," Wind Engineering, vol. 27, no. 5, pp. 351-360, 2003.

[8] H. Zhao, Q. Wu, S. Huang, M. Shahidehpour, Q. Guo, and H. Sun, "Fatigue Load Sensitivity Based Optimal Active Power Dispatch For Wind Farms," IEEE Trans. on Sustain. Energy, vol. 8, no. 3, pp. 1247-1259, Jul. 2017.

[9] R. G. de Almeida, E. D. Castronuovo, and J. A. Pecas Lopes, "Optimum generation control in wind parks when carrying out system operator requests," IEEE Trans. Power Syst., vol. 21, no. 2, pp. 718-725, May 2006.

[10] A. D. Hansen, P. E. Sørensen, F. Iov, and F. Blaabjerg, "Centralised power control of wind farm with doubly fed induction generators," Renewable Energy, vol. 31, no. 7, pp. 935-951, 2006.

[11] J. Martínez, P. C. Kjær, P. Rodriguez, and R. Teodorescu, "Comparison of two voltage control strategies for a wind power plant," in Proc. IEEE/PES Power Syst. Conf. Expo. (PSCE), 2011, pp. 1-9.

[12] Q. Guo, H. Sun, B. Wang, B. Zhang, W. Wu and L. Tang, "Hierarchical automatic voltage control for integration of large-scale wind power: Design and implementation," Electr. Power Syst. Res., vol. 120, pp. 234-241, 2015.

[13] K. Schönleber, C. Collados, R. T. Pinto, S. Ratés-Palau, and O. Gomis-Bellmunt, "Optimization-based reactive power control in HVDC-connected wind power plants, Renewable Energy, vol. 109, pp. 500-509, 2017.

[14] K. Schönleber, S. Ratés-Palau, M. De-Prada-Gil, and O. Gomis-Bellmunt, "Reactive power optimization in HVDC-connected wind power plants considering wake effects," 14th Wind Integr. Work, Energynautics GmbH, Brussels, 2015.

[15] X. Liu and X. Kong, "Nonlinear model predictive control for DFIG based wind power generation," IEEE Trans. Autom. Sci. Eng., vol. 11, no. 4, pp. 1046-1055, Oct. 2014.

[16] J. Hu, J. Zhu, and D. Dorrel, "Predictive direct power control of doubly fed induction generators under unbalanced grid voltage conditions for power quality improvement," IEEE Trans. Sustain. Energy, vol. 6, no. 3, pp. 943-950, Aug. 2015.

[17] V. Spudić, M. Jelavić, and M. Baoti, "Wind turbine power references in coordinated control of wind farms," Autom.-J. Control, Meas., Electron., Comput. Commun., vol. 52, no. 2, pp. 82-94, Jul. 2011.

[18] H. Zhao, Q. Wu, Q. Guo, H. Sun, and Y. Xue, "Distributed model predictive control of a wind farm for optimal active power control-Part II: Implementation with clustering-based piece-wise affine wind turbine model," IEEE Trans. Sustain. Energy, vol. 6, no. 3, pp. 1-10, Jul. 2015.

[19] V. Spudić, C. Conte, M. Baotić, and M. Morari, "Cooperative distributed model predictive control for wind farms," Optim. Control Appl. Methods, vol. 36, no. 3, pp. 333-352, May 2015.

[20] H. Zhao, Q. Wu, Q. Guo, H. Sun and Y. Xue, "Optimal active power control of a wind farm equipped with energy storage system based on distributed model predictive control," IET Renew. Power Gener., vol. 10, no. 3, pp. 669-677, 2016.

[21] H. Zhao, Q. Wu, Q. Guo, H. Sun, S. Huang, and Y. Xue, "Coordinated voltage control of a wind farm based on model predictive control," IEEE Trans. Sustain. Energy, vol. 7, no. 4, pp. 1440-1451, Oct. 2016.

[22] Y. Guo, H. Gao H, Q. Wu, H. Zhao, J. Østergaard, M. Shahidehpour, "Enhanced Voltage Control of VSC-HVDC Connected Offshore Wind Farms Based on Model Predictive Control," IEEE Tran Sustain Energy, vol. 9, no. 1, pp. 474-487, Jan. 2018.

[23] K. Christakou, J. LeBoudec, M. Paolone, and D.-C. Tomozei, "Efficient computation of sensitivity coefficients of node voltages and line currents in unbalanced radial electrical distribution networks," IEEE Trans. Smart Grid, vol. 4, no. 2, pp. 741-750, Jun. 2013.

[24] J. D. Grunnet M. Soctani, T. Knudsen, M. Kragelund, and T. Bak, "Aeolus toolbox for dynamic wind farm model, simulation and control," in Proc. Eur. Wind Energy Conf. Exihib., Warsaw, Poland, Apr. 2010, pp. 1-10. 
[25] G. Chen and Z. J. Guo, "Distributed secondary control for droop-controlled autonomous microgrid," in Proc. 34th Chin. Control Conf., Hangzhou, China, 2015, pp. 9008-9013.

[26] R. Olfati-Saber and R. M. Murray, "Consensus problems in networks of agents with switching topology and time-delays," IEEE Trans. Autom. Control, vol. 49, no. 9, pp. 1520-1533, Sep. 2004.

[27] Q. Shafiee, C. Stefanovic, T. Dragicevic, P. Popovski, J. C. Vasquez, and J. M. Guerrero, "Robust networked control scheme for distributed secondary control of islanded microgrids," IEEE Trans. Ind. Electron., vol. 61, no. 10, pp. 5363-5374, Oct. 2014.

[28] H. Gao, B. MA, "A longitudinal differential protection channel delay model based on the probability distribution," Power system protection and control, vol. 42 no. 17, 2014. 